\title{
Anatomia foliar de Trilepis lhotzkiana Nees e Trilepis ciliatifolia T. Koyama (Cyperaceae) Juss. ${ }^{1}$
}

\author{
Rosani do Carmo de Oliveira Arruda ${ }^{2,4}$ e Lea de Jesus Neves ${ }^{3}$
}

Recebido em 30/11/2004. Aceito em 24/05/2005

\begin{abstract}
RESUMO - (Anatomia foliar de Trilepis lhotzkiana Nees e Trilepis ciliatifolia T. Koyama (Cyperaceae) Juss.). São apresentadas informações sobre a anatomia foliar de Trilepis lhotzkiana e Trilepis ciliatifolia, duas espécies de Cyperaceae que ocorrem em formações graníticas do Estado do Rio de Janeiro e que apresentam grande semelhança morfológica. Os resultados mostram que as espécies possuem algumas características em comum, tais como: epiderme uniestratificada com corpos cônicos de sílica, estômatos do tipo paracítico, tricomas unicelulares, feixes vasculares colaterais. O esclerênquima é bastante desenvolvido estando particularmente associado ao sistema vascular, formando extensões de bainha lignificadas. O tecido clorofiliano é restrito a câmaras situadas entre os feixes vasculares. A organização e características das células epidérmicas, a presença de hipoderme lignificada contínua e a de fibras dispersas no mesofilo são caracteres úteis na separação das espécies estudadas. A estrutura foliar em ambas as espécies mostra caracteres anatômicos xeromorfos que podem estar relacionados às condições ambientais em que vivem.
\end{abstract}

Palavras-chave: Cyperaceae, plantas rupícolas, anatomia foliar

\begin{abstract}
Leaf anatomy of Trilepis lhotzkiana Nees and Trilepis ciliatifolia T. Koyama (Cyperaceae) Juss.). The present study deals with the leaf anatomy of two species of Cyperaceae: Trilepis lhotzkiana and Trilepis ciliatifolia. Both species grow on granitic outcrop from Rio de Janeiro State, Brazil. The results reveal that they present commom features as: single-layered epidermis, with conical silica bodies, paracitic stomata, unicellular hairs and collateral vascular bundles. The sclerenchyma is well developed and is associated with the vascular tissues forming lignified bundles sheath extensions. Chlorenchyma is restricted to sectors between vascular bundles. The arrangement and particularities of epidermal cells and the presence of a continuous lignified hypodermis are particularly important for taxonomic use. The leaf structure of both species have shown xeromorphic characters that can be related environmental conditions.
\end{abstract}

Key words: Cyperaceae, rock outcropping plants, foliar anatomy

\section{Introdução}

A família Cyperaceae Juss., constituída por aproximadamente 4.000 espécies agrupadas em 70 gêneros, tem distribuição cosmopolita, ocorrendo em regiões temperadas, tropicais e desertos frios (Koyama \& Maguire 1965; Cronquist 1981; Chowdhery \& Rao 1990). Em função da acentuada redução floral e da complexa estrutura da inflorescência, diversos trabalhos têm sido feitos objetivando oferecer novos subsídios que possam ser empregados na solução dos problemas taxonômicos relacionados a essa família. Diferentes autores vêm utilizando resultados qualitativos e quantitativos sobre a anatomia de escapos, rizomas, raízes e folhas como um recurso efetivamente importante na identificação e separação de gêneros e/ou de espécies (Koyama 1966; Metcalfe 1969; 1971, Standley 1986; Muniz \& Shepherd 1987; Alves et al. 2002).

No Brasil, ocorrem de 500 a 600 espécies de Cyperaceae distribuídas em 44 gêneros (Luceño \& Alves 1997). São encontradas em hábitats diversos como matas, campos de altitude, brejos, cerrados, áreas arenosas e lagoas (Barreiros 1970; Muniz \& Shepherd 1987; Costa et al. 1988; Barros 1998). Em afloramentos rochosos graníticos, no Estado do Rio de Janeiro, destacam-se duas espécies de Trilepis Nees, gênero que ocorre apenas no Brasil e na África, considerado um dos mais primitivos da tribo

Parte da Dissertação de Mestrado da primeira Autora (Bolsista CAPES)

2 Universidade Federal do Estado do Rio de Janeiro, Centro de Ciências Biológicas da Saúde, Escola de Ciências Biológicas, Departamento de Botânica, Avenida Pasteur 458, Urca, CEP 22290-240, Rio de Janeiro, RJ, Brasil

3 Universidade Federal do Rio de Janeiro, Museu Nacional, Departamento de Botânica, Quinta da Boa Vista, CEP 20940-040, São Cristóvão, Rio de Janeiro, RJ, Brasil

4 Autor para correspondência: rosaniarruda@hotmail.com 
Lagenocarpeae (Gilly 1943; Koyama \& Maguire 1965). Trilepis lhotzkiana Nees e Trilepis ciliatifolia T. Koyama, juntamente com algumas pteridófitas, licófitas e outras angiospermas são importantes componentes da flora rupícola tolerante à dessecação e relacionadas à colonização desse tipo de ambiente (Meirelles et al. 1997). Informações sobre a anatomia do gênero Trilepis são escassas podendo-se mencionar os trabalhos de Pfeiffer (1927) e Metcalfe (1971) que apresentaram dados gerais sobre a família.

Considerando a semelhança morfológica apresentada pelos táxons do gênero Trilepis, o presente estudo traz informações a respeito da anatomia foliar das espécies citadas objetivando fornecer novos dados aos trabalhos de taxonomia e sistemática, e ainda, contribuir para a ampliação do conhecimento do gênero e da família Cyperaceae.

\section{Material e métodos}

Para o desenvolvimento deste trabalho foram empregadas folhas adultas de Trilepis lhotzkiana Nees e Trilepis ciliatifolia T. Koyama de indivíduos encontrados, respectivamente, em afloramentos rochosos de Niterói (Pedra de Itacoatiara) e Santa Maria Madalena (Pedra du Bois), municípios do Estado do Rio de Janeiro. Exsicatas de Trilepis lhotzkiana e Trilepis ciliatifolia foram depositadas no Herbário do Museu Nacional sob os números R182774 e R182773, respectivamente. Para o estudo anatômico foram utilizadas folhas adultas conservadas em etanol $70 \%$ (Jensen 1962), cortadas à mão livre, clarificadas e coradas pela mistura safranina-azul de astra (Bukasch 1972 modificado por Kraus \& Arduin 1997). Para análise da epiderme foram utilizados fragmentos dissociados pela solução de Schultze (Sass 1951), corados em safranina aquosa $1 \%$. Os estômatos foram classificados de acordo com a terminologia de Metcalfe (1971) para ciperáceas. Foram realizados os testes histoquímicos usuais para identificação de paredes primárias (Strasburger 1924), paredes secundárias lignificadas (Foster 1949), amido (Johansen 1940), substâncias fenólicas (Johansen 1940) e sílica (Netolitzki 1935). Para obtenção das fotografias em microscopia eletrônica de varredura (MEV) foram empregadas folhas adultas não senescentes, fixadas em FAA (Johansen 1940), submetidas à desidratação etanólica, posteriormente, ao ponto crítico do $\mathrm{CO}_{2}$, metalizadas em ouro e analisadas em microscópio Autoscan (ETEC), $20 \mathrm{kV}$, pertencente ao CEPEL/ Universidade Federal do Rio de Janeiro e no EMV-
940 Zeiss, do Instituto de Biociências/Universidade de São Paulo. As fotografias em microscopia de luz foram realizadas no microscópio Ortomat (Ortoplan), e os diagramas, realizados em microscópio acoplado a câmara clara pertencentes ao Laboratório de Anatomia Vegetal do Museu Nacional. Em todos os equipamentos as escalas foram obtidas nas mesmas condições ópticas das imagens.

\section{Resultados e discussão}

A epiderme foliar de Trilepis lhotzkiana e Trilepis ciliatifolia, mostra-se, em vista frontal, constituída por células de tamanhos variados e formato retangular, dispostas segundo o maior eixo da lâmina (Fig. 1, 5, 15, 18). Essas características estão de acordo com as citadas por Metcalfe (1971) e por Pfeiffer (1927) para o gênero.

Em ambas as faces da folha de Trilepis lhotzkiana nota-se constante organização das células epidérmicas em faixas costais (localizadas sobre as nervuras) e intercostais (região entre as nervuras) (Fig. 1, 5, 6). Em Trilepis ciliatifolia este arranjo é observado somente na face abaxial (Fig. 18). Em Trilepis lhotzkiana as faixas costais são compostas, em ambas as faces, por fileiras de células que exibem paredes anticlinais retas ou levemente curvas e espessadas (Fig. 5, 6). Essas células se destacam por conter corpos de sílica, ocorrendo um por célula na face adaxial e em números variáveis na abaxial. O corpo silicoso tem formato cônico com ápice pontiagudo e recurvado que rompe, eventualmente, a parede periclinal externa (Fig. 3, 4) da célula que o contém. $\mathrm{Na}$ face adaxial de Trilepis ciliatifolia, onde não se observa organização em faixas costais e intercostais, todas as células epidérmicas têm paredes anticlinais sinuosas e a maior parte contêm corpos silicosos (Fig. 15). Nessa espécie as inclusões silicosas são cônicas e exibem pequenas dimensões podendo-se observar até dez por célula (Fig. 15, 17). Diversas funções têm sido atribuídas à sílica presente em células vegetais de diferentes grupos de plantas. Do ponto de vista fisiológico a sílica é tida como um elemento que afeta o crescimento, as taxas de transpiração, frutificação e o metabolismo de certos nutrientes (Sendulsky \& Laboriau 1966; Lewin \& Reimann 1969; Myiake \& Takahashi 1985; Marshener 1986). Além disso, há evidências de que a sílica fornece rigidez aos tecidos limitando a compressão causada pelos ventos além de prevenir a herbivoria (Haberlandt 1928; Mc Naughton \& Tarrants 1983). A presença de células 
epidérmicas contendo corpos silicosos, em geral, cônicos, é um importante atributo da família Cyperaceae (Metcalfe 1969; 1971) sendo a forma, número e locais de ocorrência desses cristais considerados relevantes subsídios do ponto de vista taxonômico. No presente estudo constata-se que o aspecto da parede anticlinal das células que contêm os corpos silicosos pode se constituir em caráter distintivo adicional uma vez que em Trilepis lhotzkiana mostra-se reta enquanto que em Trilepis ciliatifolia é sinuosa.

Em Trilepis lhotzkiana, na face adaxial, as células epidérmicas destituídas de corpos de sílica se destacam por apresentar espessamentos dispostos em diagonal e que conferem à parede periclinal um aspecto reticulado (Fig. 2). Em Trilepis ciliatifolia, na mesma face, células com essa característica distribuem-se aleatoriamente pela epiderme intercaladas com as células que contêm inclusões de sílica (Fig. 15). Metcalfe (1971) descreveu células com esses espessamentos parietais denominando-os de "marcas diagonais". Na face abaxial de ambas as espécies, as células desprovidas de corpos de sílica ou de espessamentos diagonais, mostram paredes anticlinais retas e superfície levemente estriada.

A sinuosidade das paredes anticlinais das células epidérmicas é referida como característica de plantas de ambientes úmidos e sombreados (Pyykko 1966). Nas espécies estudadas, no entanto, vivendo sob forte luminosidade e tolerando déficit hídrico periódico, segundo Meirelles et al. (1997), as células epidérmicas apresentam paredes bastante sinuosas. Essa sinuosidade pode ser responsável pela função mecânica desempenhada pelo sistema dérmico conferindo mais resistência à célula epidérmica evitando o colapso durante os períodos de escassez hídrica (Haberlandt 1928). A sinuosidade das paredes anticlinais das células epidérmicas pode representar, no entanto, apenas a manifestação de um caráter familiar, comum às espécies de Cyperaceae pertencentes a outros gêneros e ocorrendo em ambientes extremamente diversos.

Os estômatos observados nas espécies estudadas ocorrem nas faixas intercostais em ambas as faces da folha de Trilepis lhotzkiana (Fig. 1, 5), na face abaxial da folha de Trilepis ciliatifolia (Fig. 18) e são do tipo paracítico (Fig. 6, 19). Estômatos do mesmo tipo foram mencionados por Koyama (1966) e Metcalfe (1971), entre outros autores, para diversos gêneros de Cyperaceae.

Nas espécies ora analisadas, a epiderme que recobre a região correspondente à da nervura principal mostra-se, na face adaxial, formada por fileiras de células destituídas de corpos silicosos. Na face abaxial da folha e no bordo, células epidérmicas de paredes fortemente espessadas intercalam-se com tricomas tectores de paredes também espessadas (Fig. 12, 25, 27). Tricomas deste tipo também podem ter a parede impregnada por sílica, mas, têm pouco valor diagnóstico em função da ampla ocorrência na família (Metcalfe 1971).

A secção transversal da lâmina foliar mostra que em Trilepis lhotzkiana e Trilepis ciliatifolia a epiderme é uniestratificada em ambas as faces da folha (Fig. 7, 8, 20, 21). As células epidérmicas destituídas de corpos silicosos têm lume reduzido e paredes fortemente espessadas e cutinizadas (Fig. 7). As células dotadas de corpos de sílica são lignificadas; as paredes periclinais externas são finas e as internas muito espessadas (Fig. 8).

Sob a face adaxial da epiderme de Trilepis ciliatifolia (Fig. 22, 23) observa-se um estrato formado por 2-5 camadas de fibras às quais Metcalfe (1971) denominou de hipoderme, terminologia adotada no presente estudo. Considerando-se que a hipoderme fibrosa contínua é observada apenas em Trilepis ciliatifolia pode-se empregar essa característica como um atributo adicional na distinção de Trilepis lhotzkiana.

A secção transversal revela que a epiderme, na região da nervura central, é constituída por células buliformes (Fig. 10, 26). Essas células mostram-se volumosos, com paredes celulares espessadas e contêm compostos fenólicos. O número de camadas e a localização das células buliformes, cujas funções estão relacionadas ao dobramento e desdobramento das folhas (Mani 1964), são considerados, de um modo geral, como importantes atributos taxonômicos para as Cyperaceae. Estas células podem distribuir-se apenas na face adaxial da nervura central ou em grupos subsidiários voltados para ambas as faces da folha (Metcalfe 1971). Shepherd (1976) empregou a presença e as características das células buliformes na investigação de algumas seções do gênero Carex L. Alves et al. (2002) utilizaram o número de camadas de células buliformes na delimitação de espécies brasileiras do gênero Hypolytrum Rich.

O mesofilo em ambas as espécies exibe tendência à organização dorsiventral (Fig. 9, 22) com células dispostas de forma compacta. O parênquima clorofiliano é formado por células que exibem paredes primárias espessadas e espaços intercelulares reduzidos. Entre as células do parênquima esponjoso 

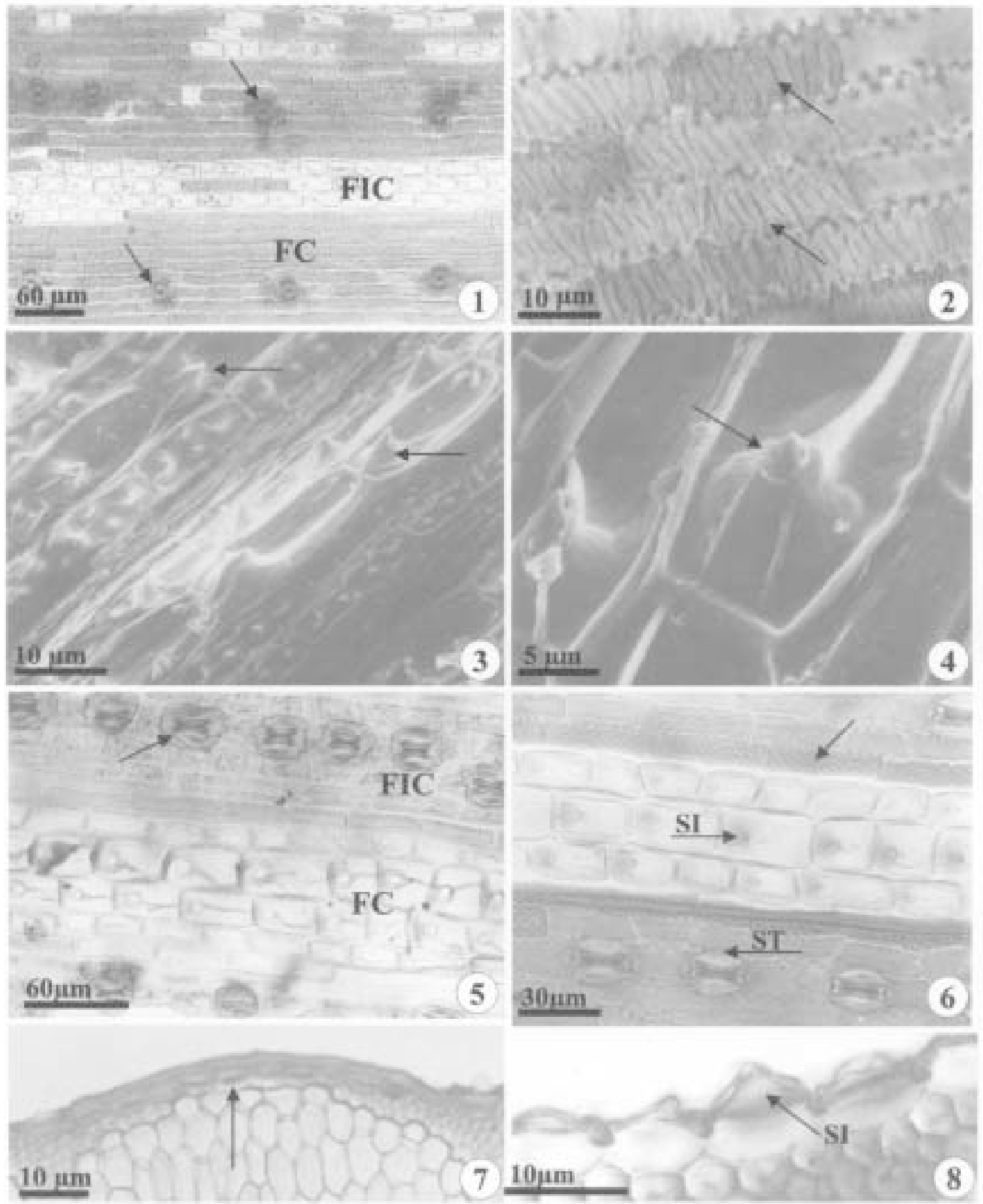

Figuras 1-8. Lâmina foliar de Trilepis lhotzkiana Nees. 1. Vista frontal da face adaxial da epiderme organizada em faixas costais (FC) e faixas intercostais (FIC) com estômatos (setas). 2. Detalhe das células epidérmicas com espessamentos diagonais (setas) nas células das faixas intercostais. 3. Aspecto geral da face adaxial da epiderme em MEV mostrando a distribuição dos corpos de sílica (setas). 4. Detalhe de um corpo cônico de sílica com ápice recurvado (seta). 5. Aspecto geral da epiderme da face abaxial em vista frontal mostrando organização em faixas costais (FC) e intercostais (FIC) com estômatos (seta). 6. Detalhe da figura anterior evidenciando a localização das células com espessamentos diagonais (seta), células da faixa costal com corpos de sílica (SI) e estômatos paracíticos (ST). 7. Células epidérmicas da faixa intercostal, face adaxial, em secção transversal destacando lúmen reduzido e paredes espessadas (seta). 8. Células epidérmicas da faixa costal, face adaxial, em secção transversal destacando corpo de sílica (SI). 

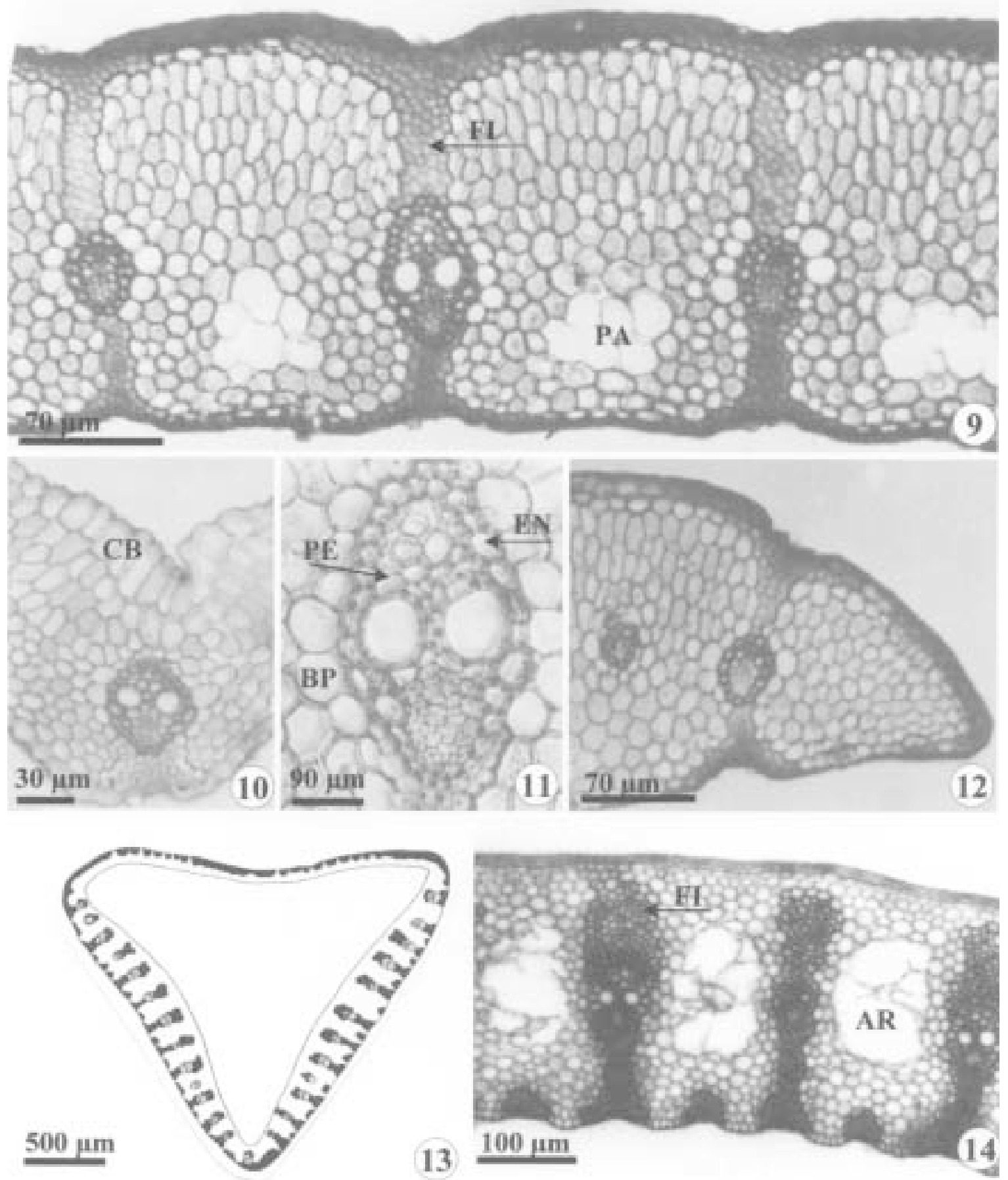

Figuras 9-14. Lâmina foliar de Trilepis lhotzkiana Nees. 9. Secção transversal da região intercostal mostrando mesofilo compacto e feixes vasculares com extensão de bainha fibrosa (FI); células de parênquima aqüifero na porção inferior do mesofilo (PA). 10. Detalhe da região da nervura principal observando-se células epidérmicas buliformes $(\mathrm{CB})$ e feixe vascular unido à face inferior da epiderme através de fibras. 11. Detalhe de um feixe vascular da região intercostal envolvido por bainha parenquimática externa (BP), endoderme (EN) e periciclo parenquimático (PE). 12. Detalhe do bordo foliar. 13. Diagrama da secção transversal da bainha foliar evidenciando a organização dos tecidos. 14. Detalhe da bainha foliar em corte destacando epiderme com paredes espessadas, grupos de fibras isolados ou associados aos feixes vasculares (FI) e a localização do aerênquima (AR). 
distribui-se um parênquima aclorofilado com células volumosas e de paredes muito finas (Fig. 9, 21, 22, 23). Essas células foram referidas por Metcalfe (1971) como células translúcidas sendo mencionadas para diversos gêneros de Cyperaceae e, possivelmente, funcionam como um tecido de reserva de água em função de suas características citológicas.

O sistema vascular de Trilepis lhotzkiana e Trilepis ciliatifolia é formado por feixes vasculares do tipo colateral (Fig. 11, 24) distribuídos em uma única fileira no mesofilo (Fig. 9, 22). Outras espécies de Cyperaceae mostram feixes vasculares do padrão colateral nas folhas: Carex L. (Shepherd 1976), Lagenocarpus Nees (Silva 2000, dados não publicados), Hypolytrum Rich (Alves et al. 2002). O feixe vascular que ocupa a região da nervura central também é do tipo colateral unindo-se apenas à face inferior da folha por meio de fibras lignificadas (Fig. 10, 26). Em ambas as espécies o floema forma uma unidade compacta, e o xilema está representado, em
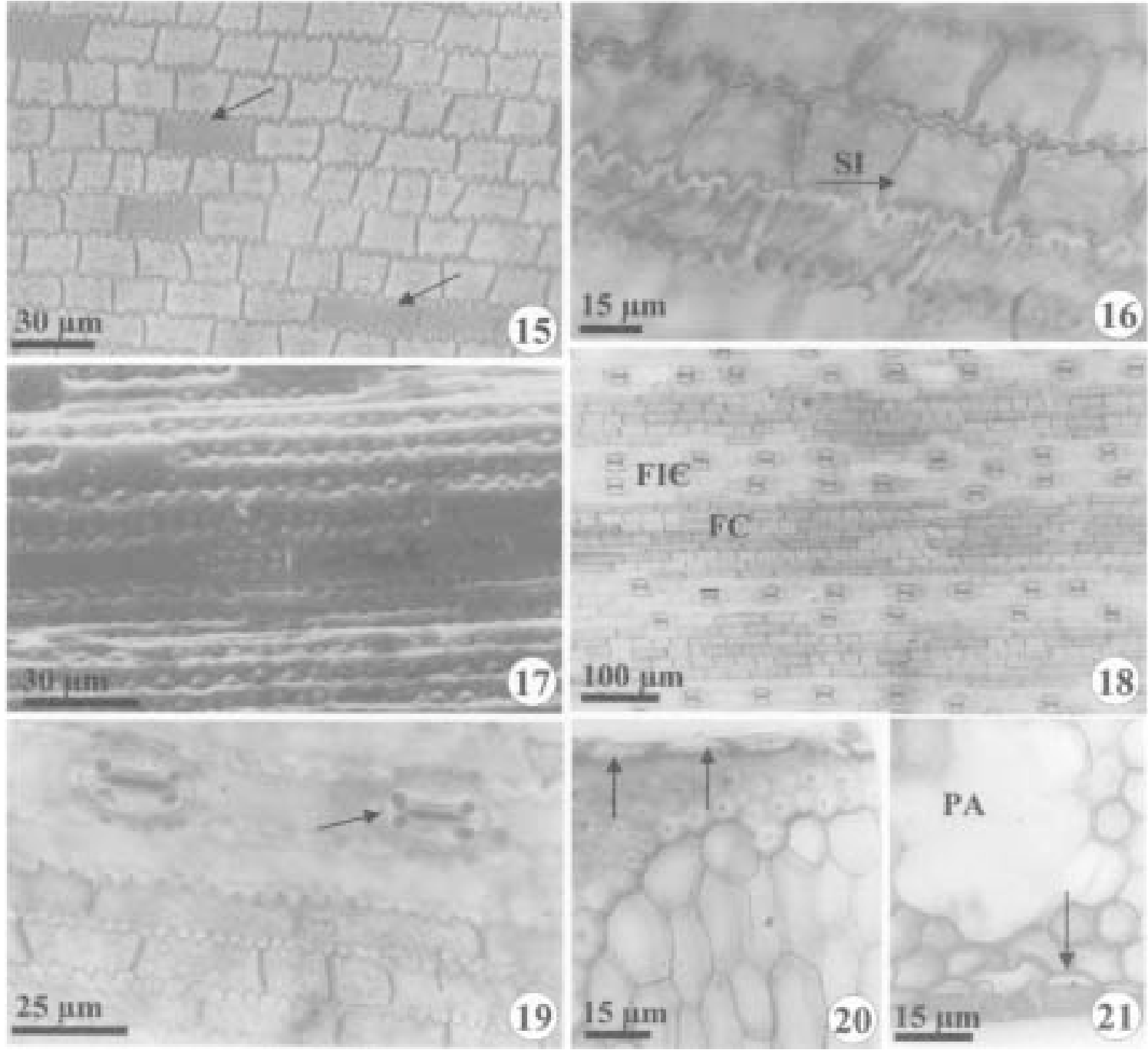

Figuras 15-21. Lâmina foliar de Trilepis ciliatifolia T. Koyama. 15. Vista frontal da face adaxial da epiderme notando-se células com paredes sinuosas organizadas em fileiras com destaque para distribuição irregular das células epidérmicas com espessamentos diagonais (setas). 15. Detalhe da figura anterior evidenciando as células portadoras de corpos silicosos (SI) e células com espessamentos diagonais. 17. Face adaxial da epiderme ao MEV mostrando o aspecto rugoso da superfície em função da presença dos corpos de sílica. 18. Aspecto geral da epiderme da face abaxial organizada em faixas costais (FC) e intercostais (FIC) com estômatos. 19. Detalhe da mesma face destacando estômatos paracíticos (seta). 20. Secção transversal da lâmina evidenciando células epidérmicas contendo corpos silicosos diminutos (setas). 21. Detalhe mostrando estômato em corte transversal e célula epidérmica com parede periclinal externa muito espessada (seta). 
quase todos os feixes, por dois grandes elementos do metaxilema separados por células de protoxilema e parênquima. Os feixes vasculares estão envolvidos externamente por células clorofiladas e com paredes primárias espessadas constituindo uma bainha parenquimática (Fig 11, 24). Internamente a essa bainha encontra-se a uma camada composta por células de paredes espessadas que apresentam reação positiva para o teste de compostos lipídicos e fenólicos constituindo, de acordo com as informações de van Fleet (1961), Esau (1965) e Menezes et al. (2003), uma endoderme (Fig. 11, 24). Internamente à endoderme observa-se, ainda, especialmente nos feixes de maior calibre (Fig. 11, 24) o periciclo, constituído de células parenquimáticas, menos evidente nas nervuras de menor calibre em acordo com o
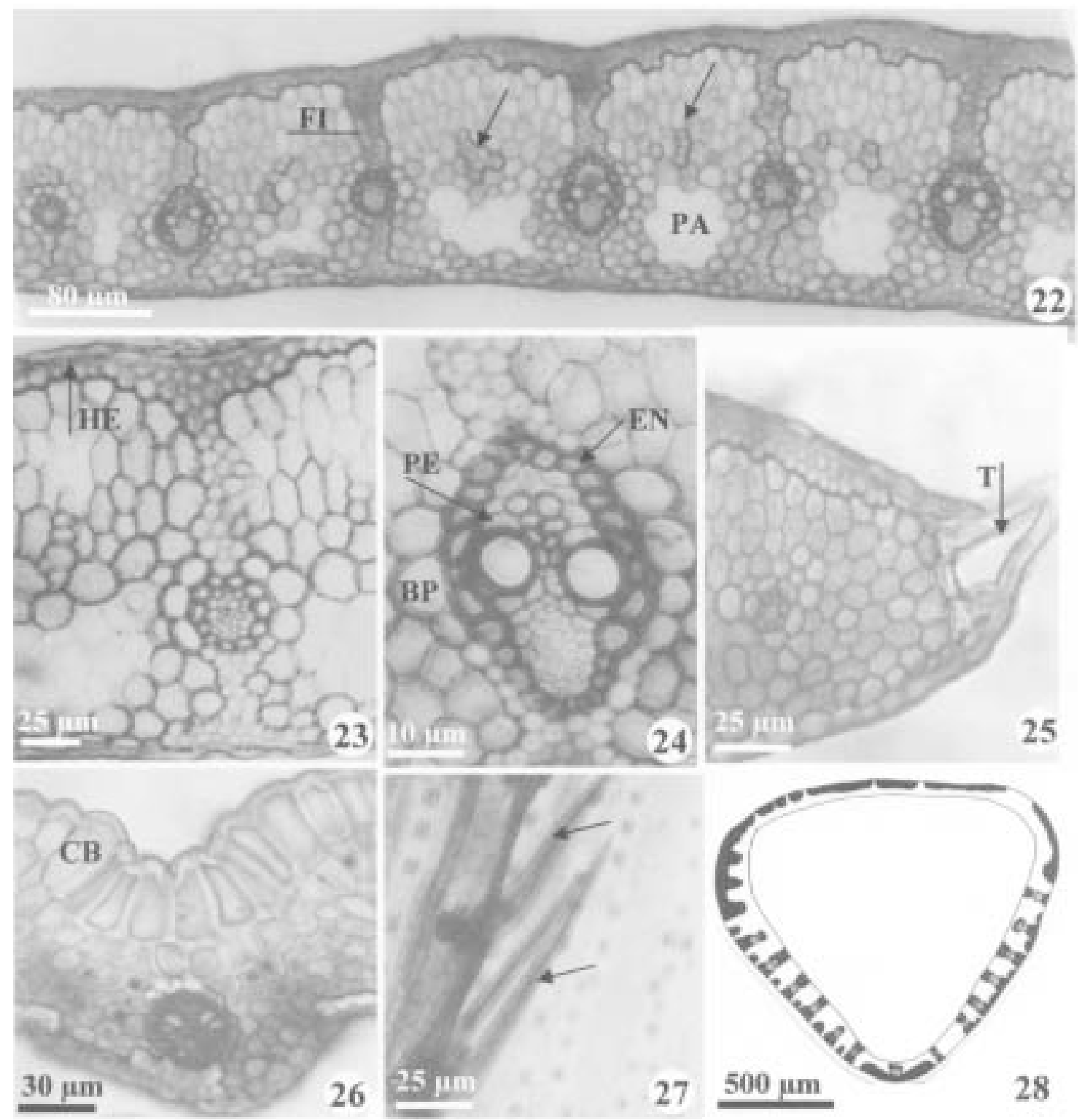

Figuras 22-28. Lâmina foliar de Trilepis ciliatifolia T. Koyama. 22. Secção transversal da região intercostal mostrando mesofilo compacto segmentado por extensões fibrosas dos feixes vasculares (FI); observam-se grupos de fibras dispersos pelo mesofilo (setas) e células de parênquima aqüífero (PA). 23. Detalhe do corte mostrando hipoderme esclerificada (HE). 24. Detalhe do feixe vascular colateral apresentando bainha parenquimática externa (BP), endoderme (EN) e periciclo parenquimático (PE). 25. Bordo foliar destacando a presença de tricoma tector com parede espessada (T). 26. Secção transversal da região da nervura principal evidenciando células epidérmicas buliformes (CB) e feixe vascular. 27. Vista frontal da epiderme na região do bordo foliar com tricomas tectores unicelulares (setas). 28. Diagrama da secção transversal da bainha foliar mostrando a organização dos tecidos. 
mencionado por Menezes et al. (2003).

Interrompendo a bainha parenquimática externa aparecem fibras de paredes espessadas e lignificadas associadas aos feixes vasculares (Fig. 9, 22, 23) formando extensões. Fibras isoladas ou formando pequenos grupos ocorrem dispersas apenas no mesofilo de Trilepis ciliatifolia (Fig. 22). As fibras conferem às folhas um caráter xeromorfo comum em plantas que crescem em ambientes desfavoráveis com deficiência hídrica e de nutrientes tais como aqueles em que ocorrem Trilepis lhotzkiana e Trilepis ciliatifolia. Essas células protegem as plantas contra a herbivoria e, assim, auxiliam-nas na conservação dos nutrientes adquiridos (Fahn \& Cuttler 1992; Turner 1994; Van Arendonk \& Poorter 1994). A ocorrência de grupos de fibras exclusivamente no mesofilo de Trilepis ciliatifolia também poderia ser empregada na identificação dessa espécie.

A bainha foliar mostra-se fechada e de secção triangular, observando-se grande similaridade na estrutura anatômica das duas espécies estudadas (Fig. $13,28)$. Essa região da folha é destituída de estômatos, e as células epidérmicas apresentam paredes espessas levemente sinuosas e destituídas de corpos silicosos. No mesofilo observam-se fibras de paredes espessadas e não lignificadas que podem estar associadas ou não ao sistema vascular (Fig. 14). Entre os feixes vasculares, em ambas as espécies, o tecido de preenchimento diferencia-se em um tecido de reserva de grãos de amido. Nessa região da folha observa-se que o parênquima de reserva de água dá lugar a um tecido rico em espaços intercelulares caracterizando um aerênquima (Fig. 14).

O estudo realizado revelou que Trilepis lhotzkiana e Trilepis ciliatifolia exibem lâmina foliar com as características comuns a muitas Cyperaceae (Metcalfe 1971). Por outro lado também foram identificadas particularidades que podem estar relacionadas à sobrevivência dessas plantas em um ambiente tão adverso como o representado pelos costões rochosos graníticos, onde a vegetação está submetida à alta incidência luminosa, déficit hídrico, ventos e herbivoria.

Os resultados obtidos mostraram, ainda, que a anatomia foliar evidenciou elementos que podem ser utilizados na distinção das duas espécies. Para Trilepis lhotzkiana verificou-se organização em faixas costais e intercostais na face adaxial, presença de células epidérmicas contendo apenas um corpo silicoso e ausência de fibras isoladas ou em grupos no mesofilo. No reconhecimento de Trilepis ciliatifolia observou-se ausência de estômatos na face adaxial da folha, presença de células silicosas com paredes anticlinais sinuosas, hipoderme esclerificada contínua sob a face adaxial da epiderme e grupos de fibras isoladas no mesofilo.

\section{Agradecimentos}

Ao Centro de Pesquisas da Eletrobrás (CEPEL) e ao Instituto de Biociências da Universidade de São Paulo (IB-USP), por franquear a utilização do microscópio eletrônico de varredura; ao Dr. Sergio Tadeu Meirelles, pela sugestão das espécies estudadas.

\section{Referências bibliográficas}

Alves, M.V.; Estelita, M.E.M.; Wanderley, M.G.L. 2002. Aplicações taxonômicas da anatomia foliar das espécies brasileiras de Hypolytrum Rich (Cyperaceae). Revista Brasileira de Botânica 25: 1-9.

Barreiros, H.S. 1970. Espécies de monocotiledôneas que ocorrem no estado da Guanabara. I. Cyperaceae (Glumiflorae). Atas da Sociedade Biológica do Rio de Janeiro 13: 167-173.

Barros, A.A. Monteiro. 1998. Caracterização limnológica preliminar da Lagoa de Jacarepiá, Saquarema, RJ. In: Anais VIII Seminário Regional de Ecologia 8: 1343-1351.

Chowdhery, H.J. \& Rao, R.R. 1990. Plant life in the Himalayan cold deserts; some adaptative strategies. Bulletin of Botany Survey of India 1/4: 45-56.

Costa, C.S.B.; Seeliger, U. \& Cordazzo, C.V. 1988. Dinâmica populacional e distribuição de Androtrichum trigunium (Spreng.) Pefeiffer (Cyperaceae) em brejos e dunas costeiras do Rio Grande do Sul, Brasil. Acta Limnologica Brasilica 2: 813-842.

Cronquist, A. 1981. An integrated system of classification of flowering plants. New York, Springer-Verlag.

Esau, K. 1965. Plant Anatomy. New York, John Willey \& Sons, Inc.

Fahn, A. \& Cuttler, D. 1992. Xerophytes. Berlin, Ed. Gerbrüder Borntraeger.

Foster, A.S. 1949. Practical Plant Anatomy. New York, D. van Nostrand Inc.

Gilly, C.L. 1943. An Afro-South American ciperaceus complex. Brittonia 5: 1-20.

Haberlandt, G. 1928. Physiological Plant Anatomy. London, Mc Millan \& Co. Ltd.

Jensen, W.A. 1962. Botanical Histochemistry. San Francisco, H.H. Freeman \& Co.

Johansen, D.A. 1940. Plant Microtechinique. New York, Paul B. Hoeber, Inc.

Koyama, T. \& Maguire, B. 1965. Cyperaceae. Tribe Lagenocarpeae. Memoirs of the New York Botanical Garden 12: 8-19.

Koyama, T. 1966. The systematic significance of leaf structure in the Cyperaceae. Mapanie. Memoirs of the New York Botanical Garden 15: 136-159. 
Kraus, J.E. \& Arduin, M. 1997. Manual Básico de Métodos em Morfologia Vegetal. Seropédica, Edur.

Lewin, J. \& Reimann, B.E.F. 1969. Silicon and plant growth. Annals Review of Plant Physiology 20: 289-304.

Luceño, M. \& Alves, M.V. 1997. Clave de los gêneros de Ciperáceas de Brasil y novedades taxonômicas y corológicas en la família. Candollea 52: 185-197.

Mani, A.P. 1964. Bulliform cells in Cyperus. Science and Culture 30: 241-242.

Marshener, H. 1986. Mineral nutrition of higher plants. London, Academic Press.

Mc Naughton, S.J. \& Tarrants, J.L. 1983. Grass leaf silification: natural selection for an inducible defense against herbivores. Proceedings of Natural Sciences 80: 790-791.

Meirelles, S.T.; Mattos, E.A. \& Silva, A.C. 1997. Potential desiccation tolerant vascular plants from Southeastern Brazil. Polish Journal of Environmental Studies 6: 17-21.

Menezes, N.L.; Silva, D.C.; Pinna, G.F.M. 2003. Folha In: B. Apezzato-da-Gloria \& S.M. Carmello-Guerreiro (eds.). Anatomia Vegetal. Viçosa, Editora UFV.

Metcalfe, C.R. 1969. Anatomy as an aid to classiying the Cyperaceae. American Journal of Botany 56: 782-790.

Metcalfe, C.R. 1971. Anatomy of Monocotyledons. V. Cyperaceae. Oxford, Clarendon Press.

Muniz, C. \& Shepherd, G.J. 1987. O gênero Scleria Berg. (Cyperaceae) no estado de São Paulo. Revista Brasileira de Botânica 10: 63-94.

Myiake, Y. \& Takahashi, E. 1985. Effect of silicon on the growth of soybean plants in a solution culture. Soil, Science and Plant Nutrition 31: 625-636.
Netolitzki, F. 1935. Das trophische parenchyn. In: K. Linsbauer (ed.). Handbuch der Pflanzenanatomie. Berlin, Gerbrüder Borntraeger.

Pfeiffer, H. 1927. Unterchungen zur vergleichenden Anatomie der Cyperaceen. I. Die Anatomie der Bläter. Beihefte zum Botanischen Centralblatt 44(1): 90-176.

Pyykko, M. 1966. The leaf anatomy of East Patagonian xeromorphic plants. Annales Botanici Fennici 3: 453-622.

Sass, J.E. 1951. Botanical Microtechinique. Iwoa, The Iowa State College Press.

Shepherd, G.J. 1976. The use of anatomical characters in the intrageneric classification of Carex (Cyperaceae). Hoehnea 6: 33-54.

Sendulsky, T. \& Labouriau, L.G. 1966. Corpos silicosos de gramíneas dos cerrados - I. Anais da Academia Brasileira de Ciências 38: 168-170.

Standley, L.A. 1986. Variation of the stomatal distribution in Carex aquatilis (Cyperaceae). American Journal of Botany 73: 1393-1399.

Strasburger, E. 1924. Handbook of Practical Botany. London, George Allen \& Nonwin, Ltd.

Turner, I.M. 1994. Sclerophylly: primarily protective? Functional Ecology 8: 669-675.

Van Arendonk, J.J.C.M. \& Poorter, H. 1994. The chemical composition and anatomical structure of leaves of grass species differing in relative growth rate. Plant, Cell and Environment 17: 963-970.

Van Fleet, D.S. 1961. Histochemistry and function of the endodermis. Botanical Review 27: 165-220. 